\title{
Aportación al estudio de las formas nominales de tratamiento en el español áureo: condiciones de selección y funciones discursivas"
}

\author{
Contribution to the Study of Nominal Forms \\ of Address in Classical Spanish: \\ Choice Conditions and Discourse Functions
}

Silvia Iglesias Recuero

Instituto Universitario Menéndez Pidal-UcM

Facultad de Filología, edif. D

Universidad Complutense de Madrid

Plaza Prof. López Aranguren s/n. Madrid, 28040

sir@ucm.es

Orcid ID 0000-0001-9570-9351

Resumen: El objeto de este artículo son los tratamientos nominales en las interacciones dialogadas en un corpus formado por seis Entremeses y dos Novelas Ejemplares de Cervantes. En la primera parte, se analizan las condiciones de selección del tipo de TN. Para poder explicar adecuadamente la selección de las formas tanto en las relaciones asimétricas o jerárquicas como, especialmente, en las simétricas en los distintos grupos sociales, se considera necesario incluir otra variable social -el estatus- junto a las ya clásicas del poder y la distancia. Tal variable está asociada al reconocimiento de la identidad y posición social de los individuos, pilar básico de las sociedades estamentales europeas. También se aboga por la conveniencia de tener en cuenta factores discursivos como las restricciones de género y la propia dinámica de la interacción. En la segunda parte, se estudian en el corpus las dos grandes funciones discursivas de los TN en las interacciones conversacionales: la organización y gestión de la conversación y su contribución a la cortesía lingüística y la gestión interrelacional.

Palabras clave: Historia del español. Pragmática histórica. Tratamientos nominales. Cortesía.
RECIBIDO: 12 DE MARZO DE 2020 ACEPTADO: 11 DE JUNIO DE 2020
Abstract: The main purpose of this paper are the conditions of use and discourse functions of nominal forms of address (NFA) in dialogical interactions. The corpus includes Cervantes's six Entremeses and two Novelas Ejemplares. In the first part, we analyse the sociopragmatic conditions for NFA selection. We highlight the relevance of adding a third variable, status, to the classic ones: power and distance, in order to adequately explain the selection of forms in both asymmetric or hierarchical relationships and symmetric ones in different social groups. This variable is associated to the acknowledgement of social identity and position, which lies at the foundation of social rganization of European modern societies. It also advocates for the convenience of including discursive factors such as genre constraints and interaction dynamical development. In the second part, we analyse the functioning of NFA at two discourse levels: conversational organization and turn management and rapport management and linguistic politeness.

Keywords: History of Spanish Language. Historical Pragmatics. Nominal Forms of Address. Linguistic Politeness.

* Este trabajo se inscribe en el Proyecto de Investigación I+D+i "Pragmática y gramática en la historia del español: la expresión de la cortesía en el español clásico” (FFI2014-53113-P). 


\section{INTRODUCCIÓN}

N

os proponemos hacer una aportación a la reconstrucción del sistema de TN en el español clásico. Como es bien sabido, las formas de tratamiento participan a la vez de la deíxis de persona -pues designan a los participantes de una interacción comunicativa $-^{1} \mathrm{y}$ de la deíxis social, pues el valor sociopragmático asociado a las distintas formas de tratamiento las convierte en "marcadores lingüísticos" de identidades y relaciones sociales (Rigatuso 2008, 354-56; Kerbrat-Orecchioni 2010). En este trabajo nos centramos en las formas nominales de tratamiento (de aquí en adelante $\mathrm{TN}$ ) para nombrar al destinatario del enunciado o alocutario, tanto cuando aparecen en función de vocativos (Sí, señora) como cuando están integradas como constituyentes oracionales (iQué quiere mi buen vecino?.). ${ }^{2}$

A diferencia del sistema de tratamientos pronominales (TP en adelante), que ha sido objeto preferente de estudio tanto para el español de esta época como posterior, ${ }^{3}$ los TN han recibido una atención menor y más fragmentaria, a pesar de su importancia en la gestión de las relaciones interpersonales. Existen para la época que estudiamos trabajos de referencia: Rigatuso (2008) estudia los TN en el español de América de los siglos XVI a XIX a partir de un riquísimo corpus fundamentalmente epistolar; Bañón (2001) ofrece un amplio panorama de su uso en el español áureo peninsular en un corpus literario muy amplio; Medina Morales (2004) aborda la expresión de las relaciones de solidaridad mediante los TP y TN en la novela picaresca. Asimismo, se han estudiado los $\mathrm{TN}$ en la comedia celestinesca (Herrero Ruiz de Loizaga), en las interacciones amorosas del siglo XVI a partir de un corpus teatral (Hamad Zahonero) o los usos prescritos en un manual de cartas (Sáez Rivera). Contamos asimismo con algún análisis de TN concretos como hermano/hermana (Bustos Gisbert). ${ }^{4}$ Además del enfoque sociolingüístico prevalente en los estudios citados, Hamad Zahonero ofrece una descripción pormenorizada de las funcio-

1. No tratamos aquí los llamados usos referenciales de los TN, esto es, las expresiones referenciales para nombrar a terceras personas en el discurso, que han sido objeto aún de menor atención, a excepción de Rigatuso (2008).

2. No incluimos vuestra merced en los TN por su ambiguo estatuto categorial en esta época y porque no aparece en función de vocativo: se mantuvo siempre como constituyente oracional desde su origen (Iglesias Recuero 2008).

3. Resulta imposible por razones de espacio dar cuenta de todos los estudios sobre TP en español. Remitimos al lector interesado a Hummel/Kluge/Vásquez Laslop y a la bibliografía contenida en los trabajos que lo componen.

4. Para la historia de otros TN como madama, ver García-Godoy en este volumen. 
nes pragmático-discursivas de los TN en las interacciones teatrales. Tenemos, pues, a nuestra disposición, datos suficientes para proceder a la reconstrucción del sistema de TN en esos siglos. Más aún cuando en estos estudios se han propuesto y discutido los efectos de distintos factores sociales tanto en la forma -recíproca o no recíproca- de uso de los tratamientos como en su selección: así se han estudiado las relaciones de poder y solidaridad, la pertenencia a distintos grupos sociales, la proyección de identidades sociales o la expresión de la (des)cortesía.

En este trabajo, de alcance modesto, se abordará el uso de los TN en las interacciones dialógicas de un corpus limitado de obras teatrales y narrativas, con el objetivo de seguir indagando en las condiciones sociopragmáticas de selección de los TN (apartado 3), así como en las funciones discursivas de su empleo en la interacción conversacional, aspecto este menos estudiado (apartado 4).

\section{CORPUS Y METODOLOGÍA}

El corpus elegido se corresponde con los seis entremeses en prosa de Cervantes: El juez de los divorcios (JD), La guarda cuidadosa (GC), El vizcaíno fingido (VF), La cueva de Salamanca (CS), El retablo de las maravillas (RM) y El viejo celoso (VC), que han arrojado un total de $315 \mathrm{TN}$, y dos novelas ejemplares: La ilustre fregona (IF) y La señora Cornelia (SC), con 216 TN (84 y 132, respectivamente). En todos ellos se han analizado los TN en sus usos como vocativo o integrados como constituyentes en la predicación oracional. La selección de obras dramáticas cae por su propio peso si se desea analizar los TN en interacciones conversacionales; por otra parte, los Entremeses, como es bien sabido, tienen un elenco relativamente amplio de personajes y situaciones comunicativas. La elección de las dos novelas tenía como objetivo servir hasta cierto punto de elemento de "control": por una parte, de los potenciales efectos que podían tener en el uso de los TN las condiciones específicas del género teatral; $y$, por otra, de las relaciones sociales representadas, dado que tanto en IF como, muy especialmente, en SC, intervienen personajes pertenecientes al grupo nobiliar, ausentes de los Entremeses. Los cambios de identidad social en IF la hacían muy recomendable para poder observar si se producían -y cómo- modificaciones anejas en los TN utilizados. También ha contribuido a la selección el hecho de que ya nos habíamos servido de este corpus en otros trabajos sobre la expresión de la cortesía en el español clásico (Iglesias Recuero 2016; 2017). 
Aunque se han analizado algunos aspectos de manera cuantitativa -en concreto, la frecuencia de TN (ver infra)-, el enfoque es eminentemente cualitativo, porque el objetivo era analizar la selección de los TN y sus funciones en la interacción conversacional. Resulta ya casi un lugar común plantear la conveniencia de emplear textos literarios en los estudios de pragmática histórica, más aún si se pretende reconstruir usos lingüísticos en las interacciones conversacionales de épocas pretéritas. Sin embargo, los textos literarios son la fuente más rica y abundante con que contamos para ello. Es necesario tener presente que cualquier género discursivo -y todo uso lingüístico se produce dentro de un género discursivo- posee sus propios condicionamientos retóricos socioculturalmente determinados, y, por tanto, cualquier fuente textual debe ser utilizada teniendo en cuenta tales condicionamientos (como tratamos de hacer en el apartado 4.1). La reconstrucción de los usos, por tanto, siempre estará condicionada por los géneros empleados como corpus textual (piénsese en la normatividad a que estaba sometido el género epistolar). Sin caer, por tanto, en la ilusión del realismo ingenuo, sí podemos pensar con cierta plausibilidad en que en una época en que el uso apropiado de los TN tenía una importancia extrema en la construcción de las identidades y las relaciones sociales, Cervantes puso en boca de sus personajes tratamientos en su mayoría habituales y adecuados a las normas de comportamiento verbal de la época, y reconocibles como tales por sus lectores. ${ }^{5}$ Precisamente, cuando Cervantes pone en boca de sus personajes usos -estratégicos o involuntarios- que se desvían de tales normas por exceso o por defecto, lo hace para conseguir patentes efectos humorísticos - que van de la comicidad a la ironía crítica- y que vienen señalados, en muchos casos, por las reacciones, unas más abiertas, otras más sutiles, de los demás personajes. Creemos, por tanto, no solo adecuado sino necesario servirnos de textos literarios para ayudar a la reconstrucción del sistema y las funciones de los TN de la época.

\section{LA SELECCIÓN DE LOS TRATAMIENTOS NOMINALES}

\subsection{Poder, distancia, grupo social y estatus en la selección de los TN}

Desde Brown y Gilman, la selección entre las distintas posibilidades de tratamientos pronominales (TP) ha sido atribuida al influjo de dos variables socia-

5. Véanse reflexiones similares en Medina Morales (2008) y Calderón Campos. 
les: el poder y la solidaridad o distancia, que explican los usos recíprocos y no recíprocos de las formas $\mathrm{T} / \mathrm{V}$. Como hemos señalado, estas dos variables han sido también utilizadas en los estudios dedicados a los TN (Bañón 2001; Medina Morales 2004; Rigatuso 2008, 355). A ellas hay que sumar ciertas características sociales de los hablantes, como la clase social o el género (Hamad Zahonero; Bustos Gisbert) y las estrategias de la gestión de las relaciones interpersonales y las identidades sociales a lo largo del desarrollo de la interacción (Bañón 2001; Rigatuso 2008; Hamad Zahonero). Todos estos aspectos se han considerado necesarios para contribuir a explicar la complejidad de la selección de los TN y de su evolución histórica.

Por nuestra parte, creemos que para ayudar a explicar la selección de los TP y los TN en la compleja sociedad estamental española -y europea- de los siglos XVI, XVII y XVIII, es indispensable recurrir a otra variable sociocultural: el estatus social, asociado a las nociones de prestigio social y honra, componentes básicos de la imagen (face) de la época (Iglesias Recuero, en prensa). Esta variable está ya implícita, aunque sin ser reconocida abiertamente como tal, en la explicación que Brown y Gilman (256) ofrecen sobre la diferencia en el uso recíproco de $\mathrm{V}$ y $\mathrm{T}$ entre iguales de las clases altas y bajas, respectivamente, en las sociedades medievales y modernas europeas: el reconocimiento mutuo de la pertenencia a un estatus alto explicaría el uso recíproco de $\mathrm{V}$ entre iguales de clase alta, $\mathrm{y}$, a la inversa, la ausencia de estatus que reconocer explicaría el uso simétrico de T entre iguales de clase baja. En nuestra opinión, este reconocimiento o atribución de estatus es fundamental para comprender los sistemas de cortesía de la época (Iglesias Recuero, en prensa) ${ }^{6} \mathrm{y}$, consiguientemente, para explicar las normas de selección de los tratamientos pronominales y nominales. ${ }^{7}$ Es bien sabido que la selección de tratamiento revestía una importancia fundamental en la gestión de las imágenes sociales de los interlocutores (y, por tanto, en la cortesía), puesto que los tratamientos constituyen los deícticos sociales por excelencia en lenguas como el español.

En los siglos XVI a XVIII se consideraba un pilar básico del orden social el reconocimiento público de la pertenencia de un individuo a un grupo social

6. Creemos que esta importancia dada al reconocimiento del estatus constituye uno de los fundamentos del estilo cortés característico de la expresión lingüística de la cortesía de la época (Rigatuso 2008), pues explica los rasgos de deferencia, formalidad y distancia que lo definen.

7. Para otros ejemplos de cómo el estatus determina la selección del tratamiento indirecto en la correspondencia oficial quinientista, ver Calderón Campos (apartado 6), en este mismo volumen. 
privilegiado; dicha pertenencia se adscribía mayoritariamente por nacimiento -es decir, correspondía a la nobleza por derecho propio- y, en segundo lugar, pero no sin contestación social, se podía adquirir a través del desempeño de cargos institucionales o por la riqueza conseguida en actividades "no mecánicas” (Maravall; Benassar; Domínguez Ortiz; Álvarez-Ossorio 1998-1999). El estatus es distinto del poder (entendido, en su sentido teórico habitual, como control sobre el comportamiento del otro) y de la solidaridad (como amalgama de relaciones heterogéneas: pertenencia al mismo grupo, familiaridad o afecto), pues tiene consecuencias específicas tanto en la selección de los TP y TN, como en otros comportamientos verbales y no verbales de la época, que no pueden explicarse a partir solamente de las otras dos variables, como esperamos mostrar a continuación. Creemos que el rasgo de deferencia que Rigatuso propone como una de las características destacadas del sistema de tratamientos en esta época $(2008,373)$ procede precisamente del cuidado por reconocer o atribuir estatus social al destinatario. ${ }^{8}$

La "semántica" del poder puede explicar bien usos no recíprocos de los TN. La situación prototípica es la relación entre amos y criados: es una relación abiertamente jerárquica, ${ }^{9}$ lo que se refleja en la asimetría en el empleo de las formas nominales de tratamiento: el amo llama por su nombre de pila, apellido o apodo al criado: Cristina, Cristinica, Argüello, Gallega (IF 158), y este devuelve siempre señor/a, o incluso amo: señor amo (IF 162). Si el criado es joven y el amo le tiene confianza o afecto, puede servirse de hipocorísticos o diminutivos: Constancica (IF 150), Cristinica, o de términos familiares como bijo/ bija (IF 157); no detectamos la misma afectividad, en cambio, en el empleo de sustantivos relativos a la edad: muchacha/o, mancebo, niña, probablemente porque remiten a otra escala entendida en la época como jerárquica, como es la edad.

Sin embargo, en otros tipos de relación de poder, como el poder institucional, la selección es más compleja. En nuestros textos aparecen cargos políticos, jurídicos, administrativos y militares: jueces y escribanos (JD), al-

8. Es por este motivo por lo que modelos de la cortesía como el de Brown y Levinson o Scollon y Scollon (cap. 3), que, a pesar de sus pretensiones de universalidad, tienen como referencia comportamientos de la sociedad actual (ver Portolés), se enfrentan a serias dificultades para dar cuenta de las normas de cortesía de sociedades pretéritas (como la estamental), que se fundamentan en una concepción muy diferente del individuo y de las relaciones sociales (ver Bax/ Kádár para un planteamiento de esta discusión).

9. En las obras analizadas los criados corresponden a las categorías de mozos de mulas o mozas de servir o limpiar, o pajes. Para otras escalas de criado, ver Bañón (2001, 74-84). 
caldes y regidores (RM), corregidores (IF), alguaciles (VC y VF) y furrieles (RM). La relación social en estos casos es diferente $-\mathrm{y}$ las normas de selección de TN también-, puesto que, si bien el detentador del cargo, en virtud del mismo, está investido de autoridad y poder legítimos sobre sus interlocutores, los administrados mantienen sus identidades sociales independientemente de esta relación. Por ello, entre cargos y administrados no siempre se produce asimetría en la selección del tratamiento. Los TN que deben recibir los funcionarios y cargos siempre incluyen el título deferencial señor, solo o, más frecuentemente, junto con la designación del cargo; a esta combinación se puede añadir el nombre propio íntegro (nombre + apellidos): señor juez, señor alguacil, señor alcalde, señor corregidor, señor regidor Fuan Castrado. Sin embargo, los administrados recibirán de ellos el TN -y el TP- que corresponda a su estatus social. En unos casos, bastará con un buena gente o un mujer de bien, como les ocurre a Mariana y su marido en JD, pues el matrimonio no parece gozar de estatus social elevado; en otros, puede ser también suficiente un simple nombre de oficio, cuando este es "plebeyo" (y, por tanto, desempeñado por plebeyos): huésped (IF 184-86). Por el contrario, con otros destinatarios de posición social elevada, el funcionario debe emplear el tratamiento señor/señora + don/doña + nombre, para hacer manifiesta su consideración a la posición social -conocida o atribuida- de su destinatario: señor don Diego (IF 197). En estas situaciones, pueden entrar en competencia el poder institucional y el estatus, pero el primero está obligado a reconocer el segundo.

Otras selecciones asimétricas deben ser atribuidas también a diferencias de estatus vinculadas a los niveles de riqueza, pues, como hemos señalado, en esta época la riqueza comenzaba a relacionarse con el estatus de manera directa, o, más frecuentemente, de manera indirecta a través de la compra y disfrute de cargos públicos. Ello explica la extensión de los títulos señor y don hacia niveles socialmente inferiores de la escala social, que comienzan a reclamar el prestigio social (la imagen o face) asociado al estatus. La desigualdad económica entre Ortigosa, la vecina alcahueta, y el matrimonio formado por Lorenza y Cañizares (¿indiano enriquecido?) puede explicar la asimetría en el trato: ella siempre los trata de mi señora doña Lorenza y Señor mío de mi alma, mientras que recibe un simple señora Ortigosa o señora vecina de ellos, sin el título doña ni ningún otro elemento deferencial. Las mismas situaciones de desigualdad económica -y, consiguientemente, social- pueden explicar la asimetría de trato entre el estudiante y los demás personajes en CS: él recibe un 
simple amigo mientras que "señorea" (Bañón 2001, 7-16) a todos sus destinatarios. ${ }^{10}$

También el estatus interviene, y de manera aún más determinante, en la expresión de las relaciones en el eje de la distancia o solidaridad, variable más compleja que el poder. Bajo esta etiqueta se han incluido relaciones interpersonales muy variadas: afecto e intimidad, grado de familiaridad o conocimiento mutuo, pertenencia a un mismo grupo, etc. (Spencer-Oatey), que pueden tener repercusiones heterogéneas en la selección del TN: así en las relaciones afectivas de amor o amistad es posible el uso recíproco del nombre de pila, mientras que la relación de vecindad, que entraría más bien en la categoría de familiaridad o conocimiento mutuo, conlleva la selección del término relacional vecino/a, con o sin el título señor/a.

Por otra parte, como ya demostró Hamad Zahonero con respecto al ámbito específico de las relaciones amorosas, en la selección del TN interviene de manera determinante la pertenencia del hablante y alocutario a un determinado grupo o clase social. Distintos grupos sociales pueden poseer distintos sistemas de TN con formas y normas de uso específicas, como ya defendió Braun (18-29) y ha comprobado Mills (cap. 4) para distintos aspectos de la cortesía. Así ocurría en la sociedad áurea española: ciertas formas de TN eran específicas de determinados grupos sociales (ver Bustos Gisbert para el TN bermana).

Y creemos que, de nuevo, esto es efecto de la variable estatus. Así, en las relaciones de amistad, mientras que la simetría o reciprocidad en el uso de los TN depende de la cercanía, confianza y afecto propios de la relación de afecto (parámetro de la solidaridad o distancia), la selección del tipo de TN depende del estamento social al que pertenecen o reclaman pertenecer los participantes. En nuestro corpus, amigos pertenecientes a la nobleza -de cualquier nivel- se tratan recíprocamente con el tratamiento complejo (señor-a) + don/ña + nombre de pila. En SC, los jóvenes caballeros D. Antonio de Isunza y Don Juan de Gamboa, "muy discretos y grandes amigos", se llaman mutuamente Don fuan (sC 246) y Don Antonio (SC 247), y añaden incluso el título señor cuando se hallan ante terceros y la interacción se convierte en pública: señor don Fuan (SC 256,

10. En estos casos de estatus dudoso el uso de formas de tratamiento de mayor deferencia a la esperada puede ser muestra de cortesía estratégica volitiva o intencional (Bravo 28) o hipercortesía (Watts, cap. 1) con intenciones adulatorias, puesto que en la época dar estatus siempre solía ser bienvenido por los beneficiados por ello. 
267), señor don Antonio (SC 267). Este es también el tratamiento en los usos referenciales: mi camarada don Antonio (SC 276). Lo mismo ocurre en IF con los nobles padres de Avendaño y Carriazo, quienes se tratan de señor don fuan (IF 191), señor don Juan de Avendaño (IF 193), y cuando designan al otro referencialmente emplean los sintagmas el señor don fuan de Avendaño (IF 193) y el señor don Diego (IF 193). ${ }^{11}$ Este hecho solo puede explicarse porque el respeto al estatus -vinculado a la pertenencia a un grupo social- se imponía a cualquiera de los parámetros de la solidaridad, al menos en las interacciones en público, y los TN actuaban como marcadores de identidad social. ${ }^{12}$

Muy al contrario, entre las clases bajas parecen no ser necesarias -ni siquiera adecuadas- tales formalidades: bastan los nombres de pila y términos de familiaridad como amigo/a o bermano/a (Bustos Gisbert); es sintomático que Avendaño y Carriazo, quienes se nombran mutuamente con señor y don en su vida de jóvenes caballeros estudiantes, pasen a tratarse recíprocamente como Tomás, Lope, hermano, amigo, e incluso con apodos como Asturiano, cuando deciden hacerse pasar por mozos de posada y de mulas. ${ }^{13}$ También en RM las dos jóvenes hijas del alcalde y del regidor se tratan de amiga, y con ese término y los nombres de pila, se llaman recíprocamente las cortesanas de VF en privado (aunque ver infra). Dentro de la clase social, la edad y el género podían ser determinantes ulteriores para el uso de términos de familiaridad como compadre (o señor compadre, ver infra), reservados en apariencia a varones adultos de los grupos plebeyos (VC, CS).

La vinculación entre los TN señor/a y don/doña con la posesión de estatus elevado -por adscripción al estado nobiliar- explica el proceso de apropiación de estos por parte de otros grupos sociales "privilegiados" económica o socialmente (ricos comerciantes y mercaderes, cargos públicos, etc.), en un proceso de "nivelación hacia arriba" (Rigatuso 2008, 371), puesto que verse tratado así suponía "adquirir estatus" o "recibir honra", en suma, verse asimilado a los niveles altos de la escala social. No es de extrañar, pues, que señor/a -y en

11. También entre mujeres jóvenes nobles, la amistad no impide el uso obligado de los títulos en los TN: señora doña fuliana llama doña Isabel a su amiga en El sagaz Estacio (SE 118). Esta marcación de estatus parece que se conserva todavía en el siglo XIX por los datos que ofrecen Medina Morales (2008); Calderón Campos y Rigatuso (2008).

12. En El caballero puntual de Salas Barbadillo hay indicaciones muy interesantes sobre la diferencia del tipo de TP que utilizaban los nobles entre sí en privado y en público.

13. Hay un uso irónico de Lope de la construcción señor + nombre de pila (señor Tomás, IF 163), construcción que indicaba respeto y consideración -deferencia- hacia un miembro del grupo social plebeyo (por la ausencia de don). 
menor medida don/doña- se generalizara (Bañón 2001) y que se prefiriera para las relaciones entre iguales o casi iguales con poca o ninguna familiaridad, donde la atribución de estatus podía ser fruto de un complicada evaluación, pues más valía dar honra que escatimarla. ${ }^{14}$ Así se produce la extensión de señor/a, para acompañar a términos de ocupación o relación social: señor/a vecinola (VF, VC), señor compadre (VC, CS), señor zapatero, señor soldado, señor sacristán (GC).

Otro aspecto relacionable con las variables del poder y del estatus y que requeriría un estudio pormenorizado es la frecuencia de uso de los TN en las interacciones. En dos sentidos: en primer lugar, es más que probable que la asimetría de la relación no solo se reflejara en la selección de la forma léxica del TN, sino en la cantidad de veces en que cada participante emplea los TN, con los locutores subordinados "obligados" a utilizar más cantidad de TN que sus superiores como forma de manifestar su respeto o acatamiento; así, los criados emplean señor/señora en una altísima proporción de sus turnos, sobre todo en posición final en las respuestas breves de acatamiento sí, señor y no, señor (IF 184) (ver también Herrero Ruiz de Loizaga 229), lo que seguramente influye en el valor de apostilla (sí señor, no señor) que termina adquiriendo la construcción (Medina Morales 2008, 145). En segundo lugar, la frecuencia de uso podría ser muy diferente en los distintos grupos sociales: las interacciones con y entre nobles exigirían una mayor frecuencia de uso de TN que las que se producen entre personajes de clases populares. Decimos esto porque frente al rango medio de un $50 \%$ de turnos con TN en los entremeses (que transcurren entre personajes de capas medias), en SC, la única obra de nuestro corpus que se desarrolla en ambiente cortesano, el porcentaje de frecuencia de TN sube al 76,51 \% de los turnos. A ello podemos añadir que en las interacciones de IF que se producen entre o hacia caballeros, prácticamente en cada turno aparece un TN. Por tanto, podría ser que el valor sociopragmático de los TN no solo residiera en los tipos de expresiones seleccionadas, sino en la frecuencia de su uso, la cual se convertiría en un índice icónico de la deferencia debida al mayor poder y estatus. Este mismo efecto lo observan Rigatuso $(2008,384)$ en la práctica epistolar y Shiina (22-23) en el teatro clásico inglés.

14. Entre otras muchas citas, baste esta de Gracián: "La cortesía siempre debe ser más que menos, pero no igual con todos, pues degeneraría en injusticia. [...] El que honra es honrado" (El arte de la prudencia, 68). 


\subsection{La construcción de la identidad social y la dinámica de la interacción: usos estratégicos de los TN}

Pero la necesidad de construir, mantener y reconocer la identidad y el estatus sociales, reales o fingidos, hace entrar en juego otros factores de la situación que, a veces, no se han tenido lo suficientemente en cuenta en el estudio de los tratamientos, y que tienen que ver, por ejemplo, con la naturaleza pública o privada de la interacción: esto es, con la presencia de otros participantes o testigos de la interacción ante los que es necesario mantener o manifestar el estatus.

Tomemos el ejemplo de las dos cortesanas de VF: Cristina y Brígida. En tanto que amigas del alma, en privado se tratan con TN propios de la familiaridad y el afecto entre las clases populares: el nombre de pila solo, Brígida, Cristina, complementado por elementos afectivos: mía, de mi alma, así como sustantivos relacionales como amiga o hermana. Sin embargo, pasan a designarse respectivamente con los títulos señora y/o doña cuando hablan con o ante terceros, con la clara intención de adoptar una identidad social superior a la que les corresponde (1a-b):

(1) a. CRistina. [a Solórzano] [...] Diga vuestra merced lo que quisiere, que la señora doña Brígida es tan mi amiga que es otra yo mismo. (VF 153)

b. BRíGIDA [a Solórzano]. [...] y que tengo yo tan buenas entradas y salidas en mi casa como la señora doña Cristina. (vF 158)

Pretensión de estatus y "honra" que es reconocida y satisfecha por todos los participantes en el inicio de la interacción:

(2) a. SolóRZano. Pero, señora doña Cristina, [...]. (VF 157)

b. CRistina. He aquí, señor don Esteban, [...]. (VF 158)

Estos mismos TN, aunque acompañados de amiga sustantivo o adjetivo, los intercambian las dos mujeres también en el momento de los saludos, actos de habla intrínsecamente corteses, en los que aparecen los TN más respetuosos:

(3) a. CRISTINA. ¡Jesús! ¿Qué es lo que traes, amiga doña Brígida, que parece que quieres dar el alma a su Hacedor?

b. BRíGIDA. Doña Cristina amiga, hazme aire, rocíame con un poco de agua este rostro, que me muero, que me fino... (VF 150$)^{15}$

15. Obsérvense las diferentes funciones de los constituyentes del vocativo: el adjetivo amiga para señalar el afecto al lado de doña para señalar estatus. Esta combinación continúa en el siglo XIX (Medina Morales 2008; Calderón Campos). 
Se podría objetar que tal atribución "antinormativa" de estatus es una estrategia cervantina para trazar un retrato psicológico y social de las protagonistas (que enlaza con el tema de conversación de esta primera escena: la desolación de Brígida ante la prohibición de uso de los coches -otro símbolo de estatusa las prostitutas); y, en efecto, lo es, pero, precisamente por ello, resalta la extrema importancia que tenía en la época la selección del TN en la construcción de la identidad social de hablantes y destinatarios.

En contraste, cuando la fiesta y los embustes están ya en marcha y, por tanto, se ha estrechado la complicidad entre ellas y Solórzano, se permiten apearse del título don/doña y pasar al que debía ser el TN de respeto adecuado a conocidos no íntimos de los grupos sociales medios urbanos: señor $/ a+n o m-$ bre de pila: señora Cristina, señor Solórzano (VF 162). Es una buena muestra de cómo influía también en la selección de TN la evolución de la interacción y de las relaciones entre los participantes.

La combinación de normas de grupo, usos estratégicos y, posiblemente, tradiciones discursivas se muestra de manera sobresaliente en el intercambio de TN entre Avendaño y Constanza en IF, donde entran en conflicto, de un lado, el deseo amoroso de Avendaño, que se reviste, como corresponde a su "verdadera" identidad social de caballero, con el ropaje del estilo cortesano, y, por otro, la renuencia de la joven, que rechaza no solo el cortejo, sino el registro lingüístico en que viene envuelto en la medida en que no se corresponde con (la idea que tiene ella de) sus identidades y posiciones sociales: recuérdese que ella cree que Avendaño es mozo de mulas, y ella es considerada por todos como la "ahijada" del ventero. Este conflicto se revela no solo en el contenido de sus intervenciones, sino de manera más sutil en la diferente selección de TN que hacen cada uno. Así, Constanza trata a Avendaño, cuando lo ve por primera vez al aparecer por la posada, de hermano, como corresponde a la igualdad social que percibe en él -por su comportamiento deduce que es un criado-, y lo designa ante el dueño de la posada con el uso referencial este mancebo (IF 150), término que también connota clase social baja (como se desprende de los ejemplos de Bañón 2001, 26-27):

(4) -¿Qué busca, hermano? ¿Es por ventura criado de alguno de los huéspedes de esta casa? (IF 150)

Pero Avendaño, ya traspasado por el amor, responde con una galantería cortesana, que convierte implícitamente a Constanza en "su señora": 
(5) -No soy criado de ninguno sino vuestro. (IF 150)

A Constanza le resulta inapropiado a su condición verse atribuida a tal estatus, por lo que insiste en el TN hermano para devolver al atrevido mozo a la que cree que es su posición en la escala social:

(6) -Vaya, hermano, norabuena, que las que servimos no hemos menester criados. (IF 150)

Sin embargo, Avendaño continúa con su cortejo y lo hace de la única manera que sabe: en el estilo cortesano. Así la trata de señora Constanza (IF 177), mientras que ella le corresponde con un simple Tomás (IF 178); lo mismo ocurre cuando el joven revela su identidad y su amor en la carta que le entrega: Constanza es Señora de mi alma, en el encabezamiento del escrito (IF 178) y señora (IF 178) en el cuerpo, expresiones ambas reservadas al amor entre caballeros y damas (Hamad Zahonero 64-73). ${ }^{16}$ Constanza vuelve a tomar con ironía la declaración amorosa y continúa tuteándole y tratándole de bermano Tomás (IF 178) o simplemente Tomás (IF 183).

Estratégico es también el muy respetuoso -y socialmente excesivo- Señora doña Cristina con que trata el platero a su vecina cortesana en contestación al mi buen vecino de ella en VF (156). Está claramente propiciado por la necesidad perentoria del platero de que la cortesana le haga un favor que va más allá de sus obligaciones como vecina, y que le induce a utilizar múltiples elementos de cortesía deferencial en la formulación de su petición: el TP vuestra merced explícito y la construcción bacer merced (Iglesias Recuero, en prensa):

(7) Platero. Señora doña Cristina, vuestra merced me ha de hacer una merced de hacer todas sus fuerzas de llevar mañana a mi mujer a la comedia, que me conviene y me importa quedar mañana en la tarde libre de tener quien me siga y me persiga. (VF 156)

En el resto de su interacción -que tiene finalidad más transaccional- se tratan de forma simétrica y más adecuada a sus identidades sociales y sus consiguientes derechos de imagen o face: señor vecino/señora vecina.

16. Para el uso de señora mía de mis ojos como tratamiento a la esposa en las cartas de llamada, ver Kluge (apartado 4.1) en este mismo volumen. 


\section{FunCIONES DISCURSIVAS DE LOS TN}

A partir de las dos funciones básicas que se le han reconocido a los vocativosTN (Zwicky; Leech; Kerbrat-Orecchioni 2010): la identificación del alocutario (deíxis personal) y la expresión de las relaciones interpersonales (deíxis social), los TN desarrollan en el discurso conversacional funciones más específicas que dependen de distintas circunstancias: el momento conversacional en que aparece el vocativo, el marco de participación, la posición del vocativo en el turno y en el enunciado, etc. Como también han señalado todos los autores, estas funciones no son incompatibles entre sí, por lo que en la mayor parte de los casos lo que se puede señalar en una función predominante, pero no única. Por nuestra parte, y siguiendo a Kerbrat-Orecchioni (2010), analizaremos dos grandes grupos de funciones discursivas, según su vinculación preferente a la organización y gestión de la conversación o a la modulación de los valores ilocutivos del enunciado y la gestión de las relaciones interpersonales. Pero antes, haremos algunas observaciones sobre lo que podrían entenderse como usos específicos y condicionados por el género discursivo.

\subsection{Género teatral, retórica y $T N$}

Hay usos de los tratamientos nominales que parecen específicos del género teatral, pues el autor necesita presentar al público a los personajes y las relaciones que mantienen entre ellos (Shiina 26). Como ha señalado KerbratOrecchioni (1996), las necesidades informativas de los participantes de las distintas capas de interacción del discurso teatral (personaje-personaje vs. autor-público) suelen ser diferentes e incluso contrarias: el público, a diferencia de los personajes, no sabe quiénes son las figuras que aparecen en escena. La transmisión de tal información al público es una cuestión realmente delicada, pues hay que satisfacer el requisito de la "naturalidad interaccional". Existen diferentes estrategias a las que el dramaturgo puede recurrir. Evidentemente, una de ellas es hacer que los personajes hagan uso de TN para nombrar a sus interlocutores en las escenas de exposición iniciales o siempre que aparece un nuevo personaje en escena: los tipos de TN permiten identificar a los personajes, atribuirles un estatus social y deducir las relaciones interpersonales existentes entre ellos. Esto es lo que ocurre en los Entremeses. Por ejemplo, la relación de desigualdad entre Ortigosa (vecina alcahueta) y la joven es- 
posa del viejo celoso se manifiesta en la selección de TN distintos y asimétricos en los turnos iniciales de la obra: señora Ortigosa/mi señora doña Lorenza; igual ocurre con la relación familiar entre esta última y la jovencita que hay en escena: señora tía/sobrina. O, a la inversa, la relación de afecto y la pretensión de estatus se refleja en los simétricos amiga doña Brígida y Doña Cristina amiga con los que se presentan las cortesanas en VF (150). Este mismo recurso es también utilizado, como hemos dicho, siempre que entran en escena personajes nuevos para el público: así el sacristán de GC aparece acompañado del $a m i-$ go Grajales (GC 140) o Cañizares de su Señor compadre, señor compadre (vC 208).

Otras apariciones de los TN quizá deberían atribuirse a la retoricidad del discurso planificado (escrito u oral): no es infrecuente que cuando algún personaje produce un largo parlamento, emplee vocativos en su inicio y en su parte conclusiva. Los TN suelen aparecer intercalados como vocativos en el enunciado que abre estos parlamentos, donde se suele hacer referencia al saber compartido por los interlocutores (Bien sabéis, señor Lorenzo Bentivolli, que... SC 274) o que constituye una llamada de atención a ellos (Yo, señores,... SC 251, Yo, señor español, soy... SC 257; Yo, señora, he servido... SC 262; Hoy bacen, señor, según mi cuenta, quince años... IF 186). También es habitual que, tras el cuerpo del parlamento, donde el hablante desarrolla una narración de eventos pasados justificadora de su comportamiento o, en otros casos, una reflexión general sobre tal situación, el movimiento discursivo hacia la conclusión consista en una vuelta al ahora y al aquí de la situación y a la interacción con los alocutarios, momento en que puede aparecer de nuevo el TN (Mirad, señor Lorenzo, si... SC 266; Digo que veáis, señor Lorenzo SC 275; Esta es, señor, la verdadera bistoria... IF 190). Funcionarían, por tanto, como índices de la estructura textual y como recordatorios de la naturaleza "conversacional" del texto.

\subsection{Los TN y la organización y gestión de la interacción conversacional}

\subsubsection{La apertura de la interacción: la llamada o interpelación}

En tanto que identificador del destinatario, una de las funciones específicas de los TN es la denominada llamada (calls, Zwicky 787; summons McCarthy/ O'Keeffe 165-66) o interpelación (Kerbrat-Orecchioni 2010, 25). Se trata de un acto de habla específico, que consiste en alertar a alguien de que se quiere iniciar una interacción con él o en atraer la atención de alguien que no nos la está prestando en ese momento. 
El TN vocativo suele ser inicial o seguir a interjecciones fáticas de interpelación como eh, oyeloiga y, en el español clásico, hola. En el corpus cervantino utilizado es rara la mera llamada de atención ("vocativo de apelación puro", Bañón 1993, 23); es más frecuente que aparezca seguido de otros enunciados propios de la apertura interaccional: saludos, peticiones o preguntas, que explicitan el motivo de tal apertura. Exige, si es reconocido, una respuesta por parte de la persona interpelada, la cual dependerá de la situación enunciativa y de los posibles actos de habla que acompañen a la interpelación.

(8) a. LoRENZA [por dentro]. ¿Cristinica? ¿ Cristinica? CRISTINA. ¿Qué quiere, tía? (vC 215)

b. CRISTINA: Señora, señora, ¡que matan a mi señor! (GC 141)

c. LeONARda. ¡Cristinica, Cristinica, tu señor es; ábrele, niña! CRISTINA. Ya voy, señora. (CS 194)

d. CRIstina: Hola, Manuel, ¿traéis vivos para una camisa? MANUEL: Sí traigo, y muy buenos. (GC 134)

e. Soldado. Hola, amigo Santa Lucía, venid acá: ¿qué es lo que queréis en esa casa? (GC 133)

f. AмO: Galán, ¿qué quiere o busca en esta puerta? (GC 139)

La marcha de un participante produce un cambio del formato de participación que puede dar lugar a la conclusión o suspensión de la interacción que estaba teniendo lugar y el inicio de una diferente, con nuevos temas o nuevas perspectivas sobre los temas anteriores. Es muy frecuente en nuestro corpus que, cuando se producen tales cambios, la nueva interacción se inicie con un TN:

(9) a. BRíGIDA. Señor don Solórzano, ¿no tendrá vuestra merced por ahí algún mondadientes para mí?... (VF 158)

b. BRíGIDA. Amiga Cristina, muéstrame esa cadena, y déjame dar con ella dos filos al deseo... (VF 161)

c. CRistina: Tío, ¿no ve cómo ha cerrado de golpe? Y creo que va a buscar una tranca... (vC 215)

d. Gobernador. Señora Autora, ¿qué poetas se usan ahora en la corte, de fama y rumbo, especialmente de los llamados cómicos? [...] (RM 174) 


\subsubsection{La selección del alocutario y la gestión de los turnos de habla}

El uso de un TN es fundamental cuando la interacción es poliádica, esto es, cuando transcurre entre más de dos participantes ratificados, para indicar si la intervención (y, por tanto, el acto de habla que contenga) va dirigida específicamente a uno de ellos (Kerbrat-Orecchioni 2010, 26-27; Defay 40; Shiina 27-28; McCarthy/O'Keefe 165; De Latte 77-78). El uso del TN hace explícito quién es el destinatario directo del enunciado o intervención al que acompaña. Suele ser necesaria su aparición cuando se produce un cambio de destinatario con respecto a los turnos conversacionales precedentes. Aunque no de manera única, la posición suele ser inicial de intervención y de turno (o aparecer inmediatamente tras interjecciones, marcadores discursivos o adverbios oracionales).

(10) a. ElLA. ¡Ay, marido mí! ¿Estáis por desgracia herido? (GC 142)

b. JUAN. Señor Autor, haga, si puede, que no salgan figuras que nos alboroten. (RM 177)

c. BENITO. Ea, sobrino, ténselas tiesas a esa bellaca jodía. (RM 180)

d. CRistina. Señora tía, éntrese allá dentro y desenójese, y deje a tío, que parece que aún está enojado. (vC 215)

e. Lorenza. Abre, Cristinica, y sepa todo el mundo mi inocencia. (VC 217)

f. CAÑZAREs. ¿Bobeas, Lorenza? Pues a fe que no estoy yo de gracia para sufrir esas burlas. (VC 215)

Si se inserta en intervenciones que requieren una respuesta necesariamente verbal del alocutario, como las preguntas, el TN funciona, además, como mecanismo explícito de selección del hablante siguiente. En estos casos, si el enunciado es breve (Leech 112; Shiina 20-21), aparece con preferencia al final del turno.

(11) a. Aмо. Ahora bien, muchacha, escoge de los dos el que te agrada [...] (GC 145)

b. ELLA. ¿Y esto es verdad, muchacha?

CRISTINA. Sí, señora. (GC 142)

c. Амо. ¿Tienes deseo de casarte, Cristinica?

CRISTINA. Sí tengo. (GC 144)

d. Capacho. ¿Véisle vos, Castrado?

JUAN. ¿Pues no le había de ver? (RM 177) 
e. QuiÑones. Dama que quedaste, tan buena como entraste.
BRÍGIDA. ¿Qué ha dicho, señor Solórzano? (VF 160)

Puede darse el caso de que un solo turno conversacional contenga intervenciones dirigidas a distintos alocutarios. Así, en el mismo turno un hablante puede comenzar con una intervención reactiva al turno del hablante anterior o a alguna circunstancia de la situación y continuar con otra, esta vez iniciativa, destinada a otro alocutario. El uso del TN es fundamental para señalar este cambio de dirección de la conversación (Cuenca 59). En nuestro corpus son frecuentísimas estas situaciones:

(12) a. SOLÓRZANO (contestando a Brígida): Ya venía él refrendado de casa. / Vuestra merced, señora Cristina, haga aderezar la cena, que yo le quiero llevar a dormir el vino... (VF 161)

b. LEONARDA. [...] [a su marido] Solo os encargo la vuelta y que no paséis del término que habéis puesto. / Tenme, Cristina, que se me aprieta el corazón. (CS 185)

c. LeONARDA. ¡Ay, desdichada! A la voz y a los golpes, mi marido Pancracio es este; algo le debe haber sucedido, pues él se vuelve. / Señores, a recogerse a la carbonera; digo, al desván donde está el carbón. / Corre, Cristina, y llévalos; que yo entretendré a Pancracio de modo que tengas lugar a todo. (CS 192)

d. Castrada: ¿Oyes, amiga? Descubre el rostro, pues ves lo que te importa. ¡Oh, qué licor tan sabroso! / Cúbrase, padre, no se moje. (RM 178)

e. CRISTinA. ¡Jesús, y qué locuras y qué niñerías! / Ríñala, tío, porque no se atreva, ni aun burlando, a decir deshonestidades. (VC 215)

f. Castrada. ¡Jesús, ¡ay de mí! ¡Ténganme, que me arrojaré por aquella ventana! ¿Ratones? ¡Desdichada! / Amiga, apriétate las faldas y mira no te muerdan... (RM 178)

g. BENITO. ¡Esta sí, cuerpo del mundo, que es figura hermosa, apacible y eluciente! ¡Hi de puta y cómo se revuelve la mochac[h]a! -/ Sobrino Repollo, tú, que sabes de castañetas, ayúdala... (RM 179)

Finalmente, el TN puede utilizarse también para la toma o apropiación del turno (Bañón 1993, 81; Shiina 29): un destinatario indirecto o testigo de la conversación de otros personajes decide intervenir: el TN, al nombrar al destinatario, anuncia la relevancia para este de tal "intromisión": 
(13) a. CRistina. Tía, la llave de loba creo que se la pone entre las faldas de la camisa. (vC 206)

b. MinjaCA [tras la secuencia de su marido y juez y procurador, se dirige al juez]. Señor juez, vuestra merced me oiga... (JD 69)

\subsection{Funciones pragmáticas de los TN en la interacción conversacional}

Los TN aparecen también con frecuencia cuando las interacciones dialógicas están ya en curso y, por tanto, no existe necesidad de identificación o selección del interlocutor. En estos casos los TN parecen desempeñar una doble función, relacionable con su naturaleza de deícticos personales y sociales: por una parte, la presencia del TN sirve para el mantenimiento o reforzamiento del contacto (Zwicky 788; Leech 108), lo que revierte sobre el impacto interlocutivo del enunciado y acentúa su valor pragmático. El hablante llama la atención del interlocutor sobre lo que se dice y le obliga a reaccionar (Cuenca 56; KerbratOrecchioni 2010, 27-28):

(14) a. SolóRZANO. Señora Cristina, al perro viejo nunca tus tus; estas tretas con los de galleruzas... (VF 162)

b. LORENZA. ¿Y la honra, sobrina? (vC 205)

c. CRISTINA. Ríñala, tío, ríñala, tío. (vC 216)

Por otra parte, la selección del TN recuerda y refuerza el tipo de relación interpersonal existente entre hablante y alocutario, por lo que puede adquirir distintos valores pragmáticos relacionados con la gestión de las relaciones sociales e interpersonales y, por tanto, también con la cortesía. Quizá sean estos los motivos por los que las investigaciones, no muy abundantes, de los valores pragmáticos de los TN en corpus conversacionales naturales o elicitados y en diálogos literarios (Bañón 1993, 73-80; Cuenca 57-58; McCarthy/O’Keeffe; Edeso Natalías; Castillo Lluch; Defay; Hamad Zahonero, cap. 4; De Latte, ap. 5.5.2; Placencia y otros) han revelado que el uso de vocativos es más frecuente acompañando a determinados actos de habla en los que la gestión de las relaciones interpersonales y las imágenes de los participantes es especialmente necesaria.

\subsubsection{Actos inherentemente corteses: saludos, despedidas y agradecimientos}

Las aperturas y cierres de las interacciones son secuencias conversacionales delicadas (Kerbrat-Orecchioni 2005, 111), desde el punto de vista de la gestión de las relaciones, porque sientan sus bases para la interacción que se abre 
y para futuras interacciones. Los TN permiten a los interlocutores delimitar la naturaleza de sus relaciones interpersonales. Por otra parte, el uso del TN personaliza en cierto sentido el acto ritual, al mostrar explícitamente que está dirigido al alocutario: ya no es tan solo un acto esperable por convención social, sino asumido por el hablante como deferencia hacia el interlocutor. Por todo ello, son especialmente frecuentes en estas secuencias conversacionales (Rigatuso 1987; Bañón 1993, 73-75; Cuenca 58-59; McCarthy/O’Keeffe 169-70; Edeso Natalías 130; Castillo Lluch 204-05; Defay 43; Hamad Zahonero, ap. 4.1; De Latte 79; Placencia y otros 563-64).

Evidentemente, la selección del tipo de TN está motivado por los parámetros de poder, estatus y solidaridad: entre conocidos y cercanos, se emplean TN que incluyen expresiones de afecto o cercanía, solas o acompañadas de expresiones de deferencia; estas últimas se hacen más frecuentes en las despedidas:

(15) a. SACRISTÁN: ¡Oh, que en buena hora estén los automedones...! (CS 190)

b. CRISTINA. Yo beso las de mi señor vizcaíno, y más adelante. (VF 159)

c. CRISTINA. ¿Jesús! ¿Qué es lo que traes, amiga doña Brígida, [...]? (VF 150)

d. CRISTINA: ¿Qué es esto, señor de mi alma? ¿Qué acelerada vuelta es esta? (CS 194)

e. CRISTINA. [...] ¿YY qué quiere mi buen vecino? (VF 156)

f. Estudiante. Señoras, soy yo, un pobre estudiante. (CS 188) ${ }^{17}$

g. Pancracio- [...] Quedad en paz, lumbre de aquestos ojos, los cuales no verán cosa que les dé placer hasta volveros a ver. (CS 187)

h. Cristina. Basta, señor vecino, vaya con Dios, que yo haré lo que me deja mandado. (VF 157).

i. Platero. [...] Y adiós, señora mía. (VF 157)

j. CaÑIZARES. Y adiós, señor compadre, que me quiero entrar en casa. (VC 210)

k. CAÑIZAREs. Y adiós, señor compadre, y perdóneme. (VC 210)

1. CRISTINA. [...] Y adiós, señoras vecinas. (VC 219)

Otros actos de habla inherentemente corteses, y que suelen aparecer con TN, y así lo hacen en nuestro corpus, son los agradecimientos y otros actos de habla

17. Hemos incluido no solo los saludos -solo dos en nuestro corpus-, sino las intervenciones que abren la interacción. 
que expresan preocupación o empatía por el interlocutor: solicitud o aportación de información sobre lo que parece que puede afectar al alocutario, ofrecimientos, consejos, consuelos, etc. (McCarthy/O'Keeffe 160-62; Edeso Natalías 130-31; Placencia y otros 564-65; De Latte 80). Como en el caso de las aperturas, la selección del TN se divide entre las expresiones de afecto y la expresión de deferencia con el generalizado señor/a, en este caso, según el grado de poder, distancia y desigualdad de estatus existente en la relación:

(16) a. BRíGIDA. Dios te lo pague, amiga, que me has consolado con tus advertimientos y consejos. (VF 152)

b. LORENZA. Aunque mi esposo está mal con las vecinas, yo beso a vuestras mercedes las manos, señoras vecinas. (VC 219)

c. BARBERO. Nuestro señor pague a vuestras mercedes la buena obra, señores míos. (CS 198)

d. CRISTINA. [...] ¿Qué es esto, señor de mi alma? ¿Qué acelerada vuelta es esta?

LEONARDA. ¡Ay, bien mío! Decídnoslo presto, que el temor de algún mal suceso me tiene ya sin pulsos. (CS 194)

f. COMPADRE. [...] ¿de qué vive descontento mi compadre? (VC 209)

g. BRÍGIDA. ¡Ay, querida, que también te toca a ti parte deste mal suceso!... (VF 150)

h. Castrada. [...] ¡ Amiga, apriétate las faldas, y mira no te muerdan! (RM 175)

i. CRISTINA. [...] Así que, amiga, no debes acongojarte. (VF 152)

j. CRISTINA. Ánimo, señora, que buen corazón quebranta mala ventura. (CS 196)

\subsubsection{Actos amenazadores de la imagen}

El otro gran grupo de actos de habla que aparecen acompañados de TN son los actos potencialmente amenazadores de la imagen del destinatario: muy especialmente, recriminaciones o reconvenciones, peticiones y respuestas no preferidas, como desacuerdos o rechazos de ofrecimientos. Creemos, al hilo de las explicaciones de otros investigadores (Kerbrat-Orecchioni 2010, 28; Defay 44-45; Edeso Natalías 133-38; Placencia y otros 564-68; De Latte 81-84; McCarthy/O'Keeffe 164 y 171-72), que los TN suelen cumplir en estas circunstancias una función compensadora de la potencial agresión a la imagen social del alocutario y a la del propio hablante, dado que todos estos actos po- 
drían poner en cuestión o en riesgo las relaciones interpersonales entre los participantes. ¿Cómo se cumple esta función compensadora? Recordar la relación interpersonal y social existente entre hablante y oyente tiene el efecto de reforzarla y puede servir como estrategia compensadora de la potencial amenaza. Cuando la relación es de muy estrecha familiaridad y afecto, la selección de un TN que expresa tal relación de manera explícita (uso de términos afectivos, nombre de pila, etc.) puede contrapesar la agresividad potencial de los actos de habla. Estaríamos, pues, ante una estrategia de cortesía positiva (Brown/Levinson 107-09):

(17) a. LeONARDA. [...] Reponce mío, habla por tu vida a lo moderno y de modo que te entienda, y no te encarames donde no te alcance. (CS 190)

b. LEONARDA. [...] pero no te pese, amigo, de hacer caridad, que vale para todas las cosas. (CS 191)

c. BRÍGIDA. ¡Ay, Cristina, no me digas eso...! (VF 152)

Cuando la relación es jerárquica o se produce entre iguales entre los que no existe excesiva familiaridad o afecto, la aparición de un título (señor) que expresa reconocimiento de poder o estatus puede tener un efecto compensatorio similar, pues el hablante estaría dando a entender que no desea ignorar su estatus o autoridad. Se trataría, pues, de la subestrategia de deferencia (Brown/Levinson 178-79): ${ }^{18}$

(18) a. CRISTINA (al sacristán que aparece bailando). Señor sacristán Reponce, no es este tiempo de danzar; dése orden de cenar, y en las demás cosas, y quédense las danzas para mejor coyuntura. (CS 192)

b. Chanfalla. No tiene vuestra merced razón, señor alcalde Repollo, de descontentarse del músico. (RM 176)

c. Chanfalla. ¡Digo, señor alcalde, que no los envía Tontonelo! (RM 180)

d. Juan. Pues, hija, ¿de antes te espantabas de los ratones y ahora pides osos y leones?

18. No siempre esta estrategia tiene el efecto esperado, como ocurre en el siguiente ejemplo, seguramente por la forma directa e intensificada en que se produce la crítica del escribano: "CAPACHO. ¡Pecador de mí, señor Benito Repollo, y qué lejos da del blanco! No dice la señora Autora que pague ninguna Antona, sino que le paguen por adelantado... / BENITO. Mirad, escribano Pedro Capacho, haced vos que me hablen a derechas..." (RM 173) 
CASTRADA. Todo lo nuevo aplace, señor padre. (RM 179)

e. Cañizares. Señores, no quiero música; yo la doy por recibida. (VC 218)

f. CRISTINA. ¿Qué dice vuestra merced, señor mío, que no le entiendo? (VF 163)

g. ORTigosa. Señor mío de mi alma, [...] me he atrevido a venir a suplicar a vuestra merced me haga tanta merced de... (vC 212)

h. Platero. Señora doña Cristina, vuestra merced me ha de hacer una merced de hacer todas sus fuerzas por llevar mañana a mi mujer a la comedia... (VF 156) $)^{19}$

Ejemplo claro de este valor compensatorio del TN es el comportamiento de Cañizares, el viejo celoso, cuando desea echar a su vecina de su casa a causa de la desconfianza -bien fundada, por otra parte- que le infunde su presencia: el TN de respeto - señora Ortigosa- con el que trata de atemperar la agresividad -de contenido y forma- de su acto de habla (váyase) desaparece con la irritación de no verse obedecido:

(19) Cañizares. Señora Ortigosa, yo no soy amigo de figuras rebozadas ni por rebozar; tome este doblón [...] y váyase de mi casa lo más presto que pudiere, y ha de ser luego, y llévese su guadamecí. [...] CAÑIZARES. Señora Ortigosa, abrevie y váyase, y no se esté agora juzgando almas ajenas. [...]

CAÑIZAREs. Abrevie, señora Ortigosa, [...].

CAÑIZAREs. ¡Aquí de Dios! ¿Qué no será posible que me deje esta vecina! ¡Ortigosa, o diablo, o vecina, o lo que eres, vete con Dios y déjame en mi casa! (VC 213-14)

No siempre los TN son elementos compensatorios (Kerbrat-Orecchioni 2010, 28; Defay 45). Como ocurre con los TP, la selección de un TN no esperado o inhabitual puede ser empleada estratégicamente para acentuar la agresión ilocutiva, que tiene su origen en el enfado o disgusto del hablante: se puede observar claramente en el siguiente ejemplo, en el contraste entre el respetuoso primer TN y el marcador de clase baja hermana (Bustos Gisbert; Herrero Ruiz de Loizaga 233-34):

19. En estos dos casos el efecto es de hipercortesía adulatoria para incitar una reacción positiva a las peticiones. 
(20) BeNITO. Señora Autora, aquí no os ha de pagar ninguna Antona, ni ningún Antoño [...] Aquí, hermana, no aguardamos a que ninguna Antona pague por nosotros. (RM 172)

Hay otro contraste, en sentido contrario, entre los empalagosos TN con que Pancracio se dirige habitualmente a su esposa y el deferencial señora, que, por inhabitual en boca del marido, se convierte en expresión de la distancia afectiva que le provoca la sospecha de la situación:

(21) PanCRaCio. ¿Estudiante encerrado en mi casa, y en mi ausencia? ¡Malo! En verdad, señora, que si no me tuviera asegurado vuestra mucha bondad, que me causara algún recelo este encerramiento [...]. (CS 194)

\section{Conclusiones}

La reconstrucción de la historia del sistema de tratamientos en español ha incidido especialmente es el estudio de los de naturaleza pronominal, lo que es lógico por su condición de mecanismo gramatical cuasi obligatorio frente a la mayor opcionalidad de los TN. Sin embargo, estos, por la riqueza y variedad de sus formas en la época áurea, resultaban imprescindibles para afinar y modular la expresión de las relaciones sociales más allá de las posibilidades que ofrecían pronombres y flexión verbal. Por ello, su análisis es complemento indispensable para que la reconstrucción sea completa.

Al lado de variables sociolingüísticas o pragmáticas ya clásicas como el poder, la distancia, la edad o el género creemos imprescindible tener en cuenta para la época áurea la del estatus, que no solo no se deja asimilar fácilmente a ninguna de ellas, sino que interfiere con ellas y tiene repercusiones en la selección de los TN (y de los TP) tanto en las relaciones simétricas como en las asimétricas. El reconocimiento -o atribución- de estatus constituía la base de la ideología de las identidades y relaciones sociales en la sociedad "cortesana" (Álvarez-Ossorio 1998) propia de la Europa estamental, y creemos que la evolución histórica de este concepto al hilo de las transformaciones económicas, políticas y culturales de las sociedades europeas y americanas está íntimamente ligado a la historia de los sistemas y los usos de los tratamientos pronominales y nominales en las distintas variedades geográficas y sociales del español.

Creemos también necesario contar con otros factores de naturaleza discursiva como son las restricciones genéricas y la dinámica de las interacciones 
para el análisis de estas formas de comportamiento verbal, pues permiten calibrar la flexibilidad del sistema de tratamientos y su adaptabilidad a las distintas intenciones y situaciones comunicativas.

Por último, el análisis del uso discursivo de los TN ha revelado dos características que creemos merecen una atención más pormenorizada: la primera tiene que ver con la frecuencia de uso de los TN que, en principio, parece ligada a las variables del poder y el estatus también en las interacciones "conversacionales", como ya señaló Rigatuso (2008) para el género epistolar en sentido amplio; habría que ver si en las interacciones "conversacionales" la evolución hacia sociedades más igualitarias ha tenido efectos de disminución en esa frecuencia. La segunda apunta a las funciones discursivas de los TN relacionadas con la gestión interpersonal y la cortesía: contamos con pocos estudios para atrevernos a extraer conclusiones definitivas, pero por el momento se puede advertir continuidad histórica tanto en su uso como estrategias de cortesía positiva y deferencial como en los tipos de actos de habla a los que acompañan preferentemente.

\section{OBRAS CITADAS}

Álvarez-Ossorio Alvariño, Antonio. "Corte y cortesanos en la monarquía de España". Educare il corpo, educare la parola nella trattatistica del Rinascimento. Eds. G. Patrizi y A. Quondam. Roma: Bulzoni, 1998. 297-365.

Álvarez-Ossorio Alvariño, Antonio. "Rango y apariencia: el decoro y la quiebra de la distinción en Castilla (ss. XVI-XVIII)". Revista de Historia Moderna: Anales de la Universidad de Alicante 17 (1998-1999): 263-78.

Bañón Hernández, Antonio Miguel. El vocativo en español: propuestas para su análisis linguiístico. Barcelona: Octaedro, 1993.

Bañón Hernández, Antonio Miguel. "Apuntes sobre el tratamiento apelativo en el Siglo de Oro español”. Tonos Digital. Revista electrónica de estudios filológicos 1 (2001): 1-109.

Bax, Marcel, y Daniel Z. Kádár. "The Historical Understanding of Historical (Im)politeness". Understanding Historical (Im)politeness. Eds. Marcel Bax y Daniel Z. Kádár. Amsterdam/Philadelphia: John Benjamins, 2012. 1-24. Benassar, Bartolomé. La España del Siglo de Oro. 1982. Barcelona: Crítica, 2001. Braun, Friederike. Terms of Address: Problems of Patterns and Usage in Various Languages and Cultures. Berlin/New York/Amsterdam: Mouton de Gruyter, 1988. 
Bravo, Diana. "Categorías, tipologías y aplicaciones: hacia una redefinición de la «cortesía comunicativa»”. Estudios de la (des)cortesía en español: categorías conceptuales y aplicaciones a corpora orales y escritos. Ed. Diana Bravo. Estocolmo: Stockholms universitet EDICE/Buenos Aires: Dunken, 2005. 2152.

Brown, Roger, y A. Gilman. "The Pronouns of Power and Solidarity". Style in Language. Ed. T. Sebeok. New York: John Wiley and Sons, 1960. 253-76.

Brown, Penelope, y Stephen Levinson. Politeness: Some Universals in Language Usage. Cambridge: Cambridge UP, 1987.

Bustos Gisbert, Eugenio. "Tratamientos nominales: hermana en el español áureo”. El español a través del tiempo: estudios ofrecidos a Rafael Cano Aguilar. Eds. Araceli López Serena, Antonio Narbona Jiménez y Santiago del Rey Quesada. Sevilla: Universidad de Sevilla, 2016. 741-53.

Calderón Campos, Miguel. "Los elementos nominales en el sistema de tratamientos del español de Andalucía durante la Restauración (1875-1931)". Formas y fórmulas de tratamiento en el mundo bispánico. Eds. Martin Hummel, Bettina Kluge y M. ${ }^{a}$ Eugenia Vásquez Laslop. México: El Colegio de México/Karl Franzes/Universität Graz, 2010. 553-70.

Castillo Lluch, Mónica. "Étude interculturelle des formes nominales de l'adresse en français et en espagnol contemporains". "Mignonne, allons voir si la rose...": Termes d'adresse et modalités énonciatives dans les langues romanes. Ed. María Helena Araujo Carreira. Paris: Université 8 Vincennes, 2008. 203-14.

Cervantes, Miguel de. Entremeses. Ed. Eugenio Asensio. Madrid: Castalia, 1985.

Cervantes, Miguel de. Novelas ejemplares. Vol. 1. Ed. Harry Sieber. Madrid: Cátedra, 1983.

Cuenca, M. Josep. "El receptor en el text: el vocatiu". Estudis Romanics 26 (2004): 39-64.

De Latte, Fien. Estudio formal-funcional y sociolingüístico del vocativo en el español madrileño. 2017. Universidad de Gante, tesis de fin de Máster. Dir. Renata Enghels. <https://lib.ugent.be/fulltxt/RUG01/002/349/216/RUG 01-002349216_2017_0001_AC.pdf>.

Defay, Emmanuel. "Les Formes nominales d'adresse dans les conversations familières". S'Adresser à autrui: Les formes nominales d'adresse en français. Dir. Catherine Kerbrat-Orecchioni. Chambéry: Université de Savoie, 2010. 31-62. 
Domínguez Ortiz, Antonio. La sociedad española en el siglo XVII, I: el estamento nobiliario. Madrid: CSIC/Granada: Universidad de Granada, 1992.

Edeso Natalías, Verónica. "Usos discursivos del vocativo en español”. Español Actual 84 (2005): 123-42.

Hamad Zahonero, Nuur. Mucho de "mi coraçón" y de "mi alma" y de "mis entrañas": tratamientos nominales en las relaciones amorosas en el siglo XV. 2015. Universidad Complutense de Madrid, tesis doctoral. Dirs. Eugenio Bustos Gisbert y Silvia Iglesias Recuero. <http://eprints.ucm.es/39781/1/ T37903.pdf>.

Herrero Ruiz de Loizaga, F. Javier. "El coloquio en el siglo XVI: cortesía, tratamiento y vocativos en la Segunda Celestina de Feliciano de Silva". Oralia 2 (1999): 221-39.

Hummel, Martin, Bettina Kluge y M. ${ }^{a}$ Eugenia Vásquez Laslop, eds. Formas y fórmulas de tratamiento en el mundo hispánico. México: El Colegio de México/Karl Franzes/Universität Graz, 2010.

Iglesias Recuero, Silvia. "Aportaciones al origen de vuestra merced". Actas del VII Congreso Internacional de Historia de la Lengua Española. Eds. Concepción Company Company y José G. Moreno de Alba. Vol. 2. Madrid: Arco Libros. 2008. 1869-84.

Iglesias Recuero, Silvia. "Otra cara de la pragmática histórica: la historia de los actos de habla en español: peticiones y órdenes en las novelas ejemplares de Miguel de Cervantes". El español a través del tiempo: estudios ofrecidos a Rafael Cano Aguilar. Coords. Araceli López Serena, Antonio Narbona, Santiago del Rey Quesada. Vol. 2. Sevilla: Universidad de Sevilla, 2016. 971-94.

Iglesias Recuero, Silvia. "Mecanismos de atenuación en las peticiones: de ayer a hoy”. LEA: Lingiüistica Española Actual 39.2 (2017): 289-316.

Iglesias Recuero, Silvia. "Pragmática histórica: peticiones y cortesía en los siglos XVI y XVII”. Actas del XI Congreso Internacional de Historia de la Lengua Española. Eds. Carlos Garatea y Álvaro Ezcurra. Berlin: Peter Lang, en prensa.

Kerbrat-Orecchioni, Catherine. "Dialogue théâtral vs. conversations ordinaires". Cabiers de Praxématique 26 (1996): 1-16.

Kerbrat-Orecchioni, Catherine. Les Actes de langage dans le discours: Théorie et fonctionnement. Paris: Armand Colin, 2005.

Kerbrat-Orecchioni, Catherine. "Introduction". S'Adresser à autrui: Les formes nominales d'adresse en français. Dir. C. Kerbrat-Orecchioni. Chambéry: Université de Savoie, 2010. 7-30. 
Leech, Geoffrey. "The Distribution and Function of Vocatives in American and English conversation". Out of corpora: Studies in bonor of Stig Fohansson. Eds. Hilde Hasselgard y Signe Oksefjell. Amsterdam: Rodopi, 1999. 107-19.

Maravall, José Antonio. Poder, honor y élites en el siglo XVII. Madrid: Siglo XXI, 1979.

McCarthy, Michael J., y Anne O'Keeffe. “«What's in a Name?»: Vocatives in Casual Conversations and Radio Phone-in Calls". Language and Computers 46 (2003): 153-85.

Medina Morales, Francisca. "Las formas nominales de tratamiento en el Siglo de Oro: aproximación sociolingüística". Memoria de la palabra (Actas del VI Congreso de la Asociación Internacional Siglo de Oro). Eds. Francisco Domínguez Matito y M. ${ }^{a}$ Luisa Lobato López. Vol. 2. Frankfurt am Main: Vervuert/Madrid: Iberoamericana, 2004. 1329-41.

Medina Morales, Francisca. "Tratamientos nominales y cortesía en la novela Peñas arriba de José María Pereda”. Forma y Función 21 (2008): 135 66.

Mills, Sarah. English Politeness and Class. Cambridge: Cambridge UP, 2017.

Placencia, María Elena, Catalina Fuentes Rodríguez y María Palma-Fahey. "Nominal Address and Rapport Management in Informal Interactions among University Students in Quito (Ecuador), Santiago (Chile) and Seville (Spain)". Multilingua 34.4 (2015): 547-75.

Portolés, José. "Cortesía pragmática e historia de las ideas: face y freedom". Onomazein 24 (2011-2012): 223-44.

Rigatuso, Elizabeth M. "Dinámica de los tratamientos en la interacción verbal: preparación y apertura conversacionales". Anuario de Lingüística Hispánica 3 (1987): 161-82.

Rigatuso, Elizabeth M. “«A su merced... de su más humilde hijo». Asimetrías e identidades en construcción: fórmulas de tratamiento y cortesía verbal en el español de Buenos Aires de la etapa colonial”. Discurso de incorporación a la Academia Argentina de Letras. Boletín de la Academia Argentina de Letras 73.297-298 (2008): 349-412.

Sáez Rivera, Daniel M. "El secretario español de Carlos Pellicer como protopragmática y catálogo de los tratamientos nominales y pronominales del español del siglo XIX". Études Romanes de Brno 36.1 (2015): 119-48.

Scollon, Ron, y Suzan Wong Scollon. Intercultural Communication: A Discourse Approach. Malden/Oxford: Wiley-Blackwell, 1995. 
Shiina, Michi. "Positioning and Functioning in Vocatives: Casework in Historical Pragmatics". Bulletin of Faculty of Letters, Hosei University 55 (2007): 17-32.

Spencer-Oatey, Helen. "Reconsidering Power and Distance". Fournal of Pragmatics 26.1 (1996): 1-24.

Watts, Richard J. Politeness. Cambridge: Cambridge UP, 2003.

Zwicky, Arnold M. "Hey, whatsyourname!". Papers from the Tenth Regional Meeting. Chicago: Chicago Linguistic Society, 1974. 787-801. 